\title{
Modeling of Stress Corrosion Cracking for High Level Radioactive- Waste Packages
}

S. C. Lu, G. M. Gordon, P. L. Andresen, and M. L. Herrera

This article was submitted to the 2003 ASME Pressure Vessels and Piping Conference, Cleveland, OH, July 20-24, 2003

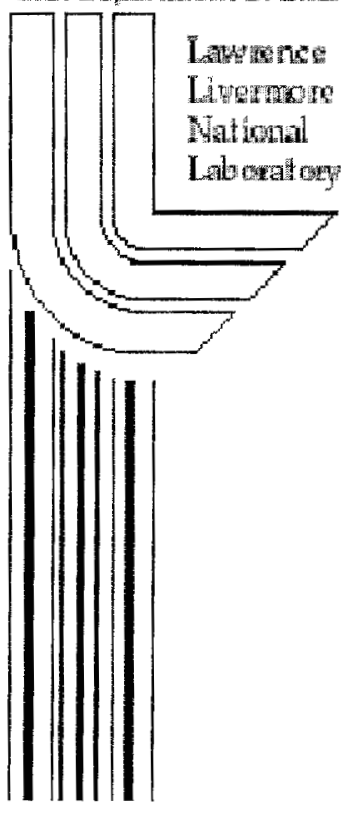

\section{June 20, 2003}


This document was prepared as an account of work sponsored by an agency of the United States Government. Neither the United States Government nor the University of California nor any of their employees, makes any warranty, express or implied, or assumes any legal liability or responsibility for the accuracy, completeness, or usefulness of any information, apparatus, product, or process disclosed, or represents that its use would not infringe privately owned rights. Reference herein to any specific commercial product, process, or service by trade name, trademark, manufacturer, or otherwise, does not necessarily constitute or imply its endorsement, recommendation, or favoring by the United States Government or the University of California. The views and opinions of authors expressed herein do not necessarily state or reflect those of the United States Government or the University of California, and shall not be used for advertising or product endorsement purposes.

This work was performed under the auspices of the U.S. Department of Energy by University of California, Lawrence Livermore National Laboratory under Contract W-7405-Eng-48. 


\title{
Modeling of Stress Corrosion Cracking for High Level Radioactive-Waste Packages
}

\author{
S.C. Lu \\ Lawrence Livermore National Laboratory \\ P.O. Box 808, Livermore, CA USA 94550 \\ e-mail: lu1@llnl.gov \\ G.M. Gordon \\ Framatome ANP \\ 1180 Town Center Drive, Las Vegas, NV USA 89144 \\ e-mail: gerald_gordon@notes.ymp.gov \\ P.L. Andresen \\ GE Global Research, One Research Circle, Schenectady, NY USA 12309 \\ e-mail: andresen@drd.ge.com \\ M.L. Herrera \\ Structural Integrity Associates, 3315 Almaden Expressway, San Jose, CA USA \\ e-mail: mherrera@structint.com
}

\begin{abstract}
A stress corrosion cracking (SCC) model has been adapted for performance prediction of high level radioactive-waste packages to be emplaced in the proposed Yucca Mountain radioactive- waste repository. SCC is one form of environmentally assisted cracking due to three factors, which must be present simultaneously: metallurgical susceptibility, critical environment, and static (or sustained) tensile stresses. For waste packages of the proposed Yucca Mountain repository, the outer barrier material is Alloy 22, a highly corrosion resistant alloy, the environment is represented by the water film present on the surface of the waste package from dripping or deliquescence of soluble salts present in any surface deposits, and the stress is principally the weld induced residual stress. SCC has historically been separated into "initiation" and "propagation" phases. Initiation of SCC will not occur on a smooth surface if the surface stress is below a threshold value defined as the threshold stress. Cracks can also initiate at and propagate from flaws (or defects) resulting from manufacturing processes (such as welding). To account for crack propagation, the slip dissolution/film rupture (SDFR) model is adopted to provide mathematical formulas for prediction of the crack growth rate. Once the crack growth rate at an initiated SCC is determined, the time to through-wall penetration for the waste package can be calculated. The SDFR model relates the advance (or propagation) of cracks, subsequent to the crack initiation from bare metal surface, to the metal oxidation transients that occur when the protective film at the crack tip is continually ruptured and repassivated. A crack, however, may reach the "arrest" state before it enters the "propagation" phase. There exists a threshold stress intensity factor, which provides a criterion for determining if an initiated crack or pre-existing manufacturing flaw will reach the "arrest" state. This paper presents the research results that quantify the threshold stress, threshold stress intensity factor, and the parameters in the crack growth rate equation based on experimental results developed specifically for Alloy 22 in environments relevant to high level radioactive-waste packages of the proposed Yucca Mountain radioactive-waste repository.
\end{abstract}




\section{INTRODUCTION}

Radioactive materials such as spent nuclear fuel and high-level radioactive waste produced by commercial electric power generation, nuclear weapons production, and research and development activities have accumulated since the mid-1940s at sites managed by the U.S. Department of Energy (DOE) and at commercial reactors and storage facilities. The responsible management and disposal of these materials is a critical part of the DOE mission to meet its obligation to dispose of high-level radioactive waste and spent nuclear fuel. Congress in 1987 direct the DOE to investigate Yucca Mountain, Nevada, exclusively, to determine whether it is a suitable site for the first geologic repository for the nation's spent nuclear fuel and high-level radioactive waste.

The engineered barrier system for the Yucca Mountain high level radioactive-waste repository is designed to complement the natural barriers in isolating waste from the environment. The core of the engineered barrier system is the waste package (WP). According to DOE (2001), typical waste packages (see Fig. 1) would have a dual-metal design containing two concentric cylinders. The inner cylinder would be made of Stainless Steel Type $316 \mathrm{NG}$ (SS 316NG) with a thickness of $5 \mathrm{~cm}(2 \mathrm{in}$.). The outer cylinder would be made of a corrosion-resistant, nickel-based alloy (Alloy 22) with a thickness ranging from 2.0 to $2.5 \mathrm{~cm}(0.8$ to $1.0 \mathrm{in}$.). Alloy 22 would protect the stainless steel inner cylinder from corrosion, and SS $316 \mathrm{NG}$ would provide structural support for the thinner Alloy 22 cylinder.

Each waste package would have outer and inner lids at each end of the cylinder. The outer (closure) lids would be made of Alloy 22 with a thickness of $2.5 \mathrm{~cm}(1.0 \mathrm{in}$.). The inner lids would be made of Stainless Steel Type 316NG with a thickness between $6.5 \mathrm{~cm}(2.6 \mathrm{in}$.) and 13 $\mathrm{cm}(5 \mathrm{in}$.) depending on the waste package design. The loading end of the waste package has a third flat closure lid made of Alloy 22, which would be placed between the inner lid of stainless steel and the outer lid of Alloy 22. The flat closure lid provides an extra barrier against a potential release caused by one form or another environmentally assisted corrosions, such as the stress corrosion cracking (SCC) in waste packages.

SCC is the initiation and propagation (or growth) of cracks due to three factors, which must be present simultaneously: metallurgical susceptibility, critical environment, and static (or sustained) tensile stresses. The discussion on SCC in this paper will be restricted to the Alloy 22 waste package outer barrier (WPOB). The stainless steel structural material is not modeled since the waste package performance assessment does not take corrosion credit from the stainless steel inner barrier of the WP. The stress which will leads to SCC in waste packages is primarily the residual stress induced by welding process. The entire waste package will be heat treated (annealed) to release the weld residual stress before the loading of waste contents and closure of the closure lids at the loading end. Therefore, the only areas of SCC concern are the closure welds of the waste package at the loading end. The treatment of SCC described in this paper is illustrated by the flow diagram shown in Fig. 2.

\section{CRACK INITIATION}

Stress corrosion cracking has historically been separated into "initiation" and "propagation" phases (Jones and Ricker 1987). For the purpose of lifetime modeling, it is appropriate that 
initiation is associated with microscopic crack formation at localized corrosion or mechanical defect sites. In the area of environmentally assisted cracking (such as SCC), coalescence of microscopically small cracks will take place and develop into deeper cracks. Andresen and Ford (1988) used a crack size of $0.05 \mathrm{~mm}(50 \mu \mathrm{m})$ to start propagating SCC cracks.

For a given alloy, metallurgical condition, set of environmental conditions, and in the absence of cyclic stresses, initiation of SCC will not occur on a 'smooth surface' (without sharp defects such as weld defects that can generate a significant stress intensity factor) if the surface stress is below a threshold value defined as the threshold stress (ASM International 1987). Recently obtained SCC crack initiation measurements under constant load conditions reported in Young et al. (2003) are summarized in Fig. 3, where the measurements of crack initiation stress is presented as applied stress ratio (the ratio of applied stress to yield strength) vs. time-to-failure (or total exposure time without failure) for specimens subjected to 9,600 hours of exposure in hot concentrated salt solution ( $\mathrm{pH}=10.3$ at $105^{\circ} \mathrm{C}$ ), known as Basic Saturated Water (BSC 2001), designed to simulate the chemistry of concentrated Yucca Mountain ground water. The test results indicated that Alloy 22 exhibits excellent SCC resistance since failure was not observed for any of the 120 Alloy 22 specimens covering a variety of metallurgical conditions (including as-welded condition). The applied stress ratios were up to about 2.1 times the yield strength (YS) of the as-received material and up to 2.0 time the yield strength of the welded material. This stress ratio corresponds to an applied stress of about 89 to $96 \%$ of the ultimate tensile strength (UTS).

Since the above SCC initiation test results are for exposures out to five years, an extrapolation scheme is needed in order to derive a defensible threshold stress value associated with the lifetime of waste packages and drip shields from the available experimental results. The ASME Boiler Pressure Vessel code (ASME 1969) typically uses a safety factor of 2 on the runout stress (endurance limit) for defining fatigue lifetime cycles. Following this precedent, the threshold stress value (criterion) may be derived from the minimum failure stress (or runout stress without failure) obtained from the constant load tests, i.e., 2.0 (YS) for Alloy 22, by applying an appropriate safety factor. Consistent with but somewhat more conservative than the ASME code precedent (to provide added margin considering the expected very long lifetimes of the WP), a stress reduction factor of 2.2 (rather than 2.0) is applied to the estimated runout stress to obtain a threshold stress value. This approach results in threshold stress values of 0.9(YS) for Alloy 22 .

\section{MANUFACTURING FLAWS}

Initial cracks can also be flaws (or defects) resulting from manufacturing processes (such as welding). The current welding process to be used for the WP final closure weld is the automated Narrow Groove Gas Tungsten Arc Welding (NG-GTAW) process (CRWMS M\&O 1996 [124950], p. 5). The expected type, size and orientation of defects that can result from the GTAW process is supported by a recent weld defect evaluation study in which sixteen full diameter 21 PWR container Alloy 22 closure weld mockup ring specimens were fabricated using a prototypical cold-wire GTAW process. Weld defects present in these rings were examined by various NDE techniques including liquid penetrant and eddy current surface examinations and volumetric radiographic and ultrasonic (UT) examinations. These were followed by metallographic destructive examination. Information gathered from these weld mockup 
experiments were used to develop flaw size and density distributions applicable to the closure welds of the WP (BSC 2003).

\section{SLIP DISSOLUTION/FILM RUPTURE MODEL FOR SCC CRACK GROWTH}

As stated earlier in this paper, initiation is associated with microscopic crack formation at localized corrosion or mechanical defect sites. In the area of environmentally assisted cracking (such as SCC), coalescence of microscopically small cracks will take place and develop into deeper cracks. Thereafter, the crack may either reach the "arrest" state or the "propagation" phase. A lifetime crack propagation prediction model can be achieved via a fundamental understanding of the cracking mechanism. For the systems of interest, the slip dissolution/film rupture mechanism has been chosen. This cracking mechanism has been successfully applied to model the SCC for stainless steel, low-alloy steel, and nickel-based alloys in light water reactor environments (Ford and Andresen 1988; Andresen and Ford 1988).

In accordance with the slip dissolution/film rupture theory, crack advance is Faradaically related to the metal oxidation that occurs when the protective film at the crack tip is ruptured. The initial oxidation rate (and, hence, crack advance rate) will be rapid, typically controlled by activation or diffusion kinetics as the exposed metal rapidly dissolves. Availability of the balancing cathodic reduction current is also clearly necessary but is generally not limiting in hot water environments. However, in most (if not all) hot water cracking systems, a protective oxide reforms at the bared surface, and the rate of total oxidation (and crack tip advance) slows with time. Thus, crack advance can only be maintained if the film rupture process is repetitive. Therefore, for a given crack tip environment, corrosion potential, and metallurgical condition, crack growth will be controlled by the change in oxidation charge density with time and the frequency of film rupture at the strained crack tip.

By invoking Faraday's law, the average environmental crack growth rate, $V_{t}$ (or da/dt where a is the crack size), can be related to the strain rate at the crack tip, $\dot{\varepsilon_{c t}}$, by the following equation (Andresen and Ford 1985):

$$
V_{t}=\frac{M}{z \rho F} \frac{Q_{f}}{\varepsilon_{f}} \dot{\varepsilon}_{c t}
$$

where $M, \rho=$ atomic weight and density of the crack tip metal

$\mathrm{F}=$ Faraday's constant

$\mathrm{z}=$ number of electrons involved in the oxidation of a metal atom

$\mathrm{Q}_{\mathrm{f}}=$ oxidation charge density per film rupture

$\varepsilon_{\mathrm{f}}=$ fracture strain of the film

The time, $\mathfrak{t}_{\mathrm{f}}$, to reach the fracture strain, $\boldsymbol{\varepsilon}_{\mathrm{f}}$, is:

$$
t_{f}=\varepsilon_{f} / \dot{\varepsilon_{c t}}
$$


Fig. 4 shows the schematic of oxidation current density vs. time following repeated oxide rupture events. Repassivation current transients exhibit an initially high bare surface dissolution current density, $i_{0}$, at an initial short time, $t_{0}$. Thereafter, oxide growth (or thickening) leads to a decay in the oxidation current density, which often follows a power law relationship:

$$
i_{t}=i_{o}\left[\frac{t}{t_{o}}\right]^{-n}
$$

where "n", the repassivation slope, is the slope on a log-log plot of $\left(i_{t} / i_{0}\right)$ vs $\left(t / t_{0}\right)$ and can be measured from the repassivation response.

The oxidation charge rate $\mathrm{Q}_{\mathrm{f}}$ in Eq. 1 is given by the following equation:

$$
Q_{f}=\int_{0}^{t_{f}} i_{t} d t=\frac{i_{o} t_{o}^{n}}{(1-n)\left(\varepsilon_{f} / \dot{\varepsilon}_{c t}\right)^{n-1}}
$$

Under these circumstances, the crack propagation rate will be given by the substitution of Eq. 4 into Eq. 1:

$$
V_{t}=\frac{M}{z \rho F} \frac{i_{O} t_{o}^{n}}{(1-n) \varepsilon_{f}^{n}}\left(\varepsilon_{c t}\right)^{n}
$$

Because of the power law relationship (Eq. 3), Eq. 1 can be reformulated as follows:

$$
V_{i}=A\left(\dot{\varepsilon}_{c t}\right)^{n}
$$

where the parameter " $\mathrm{A}$ " is related to the repassivation slope " $\mathrm{n}$ " through the following expression:

$$
A=\frac{M}{z \rho F} \frac{i_{0} t_{o}^{n}}{(1-n) \varepsilon_{f}^{n}}
$$

The initial application of the slip dissolution/film rupture model was on the quantitative prediction of cracking in austenitic type $304 / 316$ stainless steels in $288^{\circ} \mathrm{C}$ high-purity BWR water (Ford and Andresen 1988). The model quantification processes can be summarized by the following steps:

Step 1 - Measurements of $\mathbf{n}$ can be obtained from repassivation tests based on the assumption that the repassivation current follows a power law response (Eq. 3). Those tests typically involve rapidly straining wires to increase the anodic passive current density, and subsequently measuring the decay of the passive current density with time. 
Step 2 - Once $\mathrm{n}$ is known, the value of $\mathrm{A}$ can be determined from Eq. 7 which relates the parameters "A" and " $n$ " to the specific oxidation rates and the fracture strain of the oxide at the crack tip.

An alternative procedure, however, is used to quantify the model parameters. Based on this procedure, "A" can be directly determined from " $n$ " empirically. The empirical determination of $A$ is based on SCC crack growth tests that measure the crack growth rate $V_{t}$ at specific crack tip strain rate $\dot{\varepsilon}_{c t}$. The value of $\mathrm{A}$ is calculated in accordance with Eq. 6 for each set of $\mathrm{n}, \mathrm{V}_{\mathrm{t}}$ and $\dot{\varepsilon}_{c t}$. Curve fitting is then used to develop the empirical relationship between $\mathrm{A}$ and $\mathrm{n}$.

An empirical relationship between $\mathrm{A}$ and $\mathrm{n}$ (with $\mathrm{A}$ in $\mathrm{mm-s} \mathrm{s}^{(\mathrm{n}-1)}$ and $\mathrm{n}$ being dimensionless),

$$
\mathrm{A}=7.8 \times 10^{-2} \mathrm{n}^{3.6}
$$

has been given by Ford and Andresen (1988) for 304 stainless steel in $288^{\circ} \mathrm{C}$ water.

Substitution of Eq. 8 into Eq. 6 leads to:

$$
V_{t}=7.8 \times 10^{-2} n^{3.6}\left(\dot{\varepsilon}_{c t}^{*}\right)^{n}
$$

where $\mathrm{V}_{\mathrm{t}}$ has the unit of $\mathrm{mm} / \mathrm{s}$ and $\dot{\varepsilon}_{c t}$ has the unit of $\mathrm{s}^{-1}$.

For constant load conditions, the crack tip strain rate, $\dot{\varepsilon}_{c t}$ in Eq. 9 is related to the engineering stress parameters (such as the stress intensity factor $\mathrm{K}_{\mathrm{I}}$ ) via the semi-empirical formulation in Andresen and Ford (1988):

$$
\dot{\varepsilon_{c t}}=4.1 \times 10^{-14} K_{I}^{4}
$$

where the stress intensity factor $\mathrm{K}_{\mathrm{I}}$ is in $\mathrm{MPa}(\mathrm{m})^{1 / 2}$.

For constant load, substituting Eq. 10 in Eq. 9 leads to the following alternative crack growth rate equation:

$$
V_{t}=7.8 \times 10^{-2} n^{3.6}\left(4.1 \times 10^{-14}\right) n\left(K_{I}\right)^{4 n}
$$

or,

$$
V_{t}=\bar{A}\left(K_{I}\right)^{\bar{n}}
$$

where

$$
\overline{\mathrm{A}}=7.8 \times 10^{-2} \mathrm{n}^{3.6}\left(4.1 \times 10^{-14}\right) \mathrm{n}
$$




$$
\overline{\mathrm{n}}=4 \mathrm{n}
$$

For Alloy 22 under constant load condition, the parameter " $n$ " can be determined from Eq. 11 based on crack growth rates measured at various levels of applied stress intensity factor, $\mathrm{K}_{\mathrm{I}}$. Recent SCC crack growth rate measurements from Andresen et al. (2003) have been made available for the quantification of parameters for the SDFR SCC model to be used for Alloy 22. The test data were developed from four Alloy 22 specimens tested at $110^{\circ} \mathrm{C}$ in a concentrated mixed salt environment. The specimens were subjected to cyclic loading in order to initiate crack growth and then followed by constant loading conditions with various hold times. The set of test data to be used as input for establishing value of $\mathrm{n}$ for Alloy 22 are summarized in Table 1 . These data were selected based on a minimum hold time of 24 hours (or 85,400 seconds) because Eq. 11 is applicable only to constant loading condition. It is unrealistic to determine the parameter $\mathbf{n}$ in this equation based on test data at relative short hold times. The only exception is the data point associated with specimen c144 for which the hold time is relatively short $(3,000$ seconds or approximately one hour) but cracking appeared to cease, i.e., reaching the constant load state.

Table 1. Summary of source data for Alloy 22 SDFR model quantification.

\begin{tabular}{|c|c|c|c|c|c|}
\hline Specimen & $\begin{array}{c}\text { Hold time, } \\
\text { hours }\end{array}$ & $\begin{array}{c}\text { Tested stress } \\
\text { intensity } \\
\text { factor, } \\
\mathrm{MPa}(\mathrm{m})^{\wedge} .5\end{array}$ & $\begin{array}{c}\text { Measured } \\
\text { Crack Growth } \\
\text { Rate, } \mathrm{mm} / \mathrm{s}\end{array}$ & $\begin{array}{c}\text { Source (page \# } \\
\text { of DTN: } \\
\text { L02110531221 } \\
5.023\end{array}$ & $\begin{array}{c}\text { Calculated } \\
\text { "n" value } \\
\text { (see Note 3) }\end{array}$ \\
\hline $\mathrm{c} 153$ & $\mathrm{CL}^{\text {Note }}$ & 30 & $2.50 \mathrm{E}-10$ & p. 11 & 1.1680 \\
\hline $\mathrm{c} 153$ & $\mathrm{CL}^{\text {Note } 1}$ & 30 & $5.00 \mathrm{E}-10$ & $\mathrm{p} .11$ & 1.1190 \\
\hline $\mathrm{c} 144$ & 1 & 30 & $1.00 \mathrm{E}-11^{\text {Note } 2}$ & p. 7 & 1.3910 \\
\hline $\mathrm{c} 152$ & 24 & 45 & $1.00 \mathrm{E}-11^{\text {Note }}$ & p. 10 & 1.5630 \\
\hline $\mathrm{c} 152$ & 24 & 45 & $4.00 \mathrm{E}-10$ & $\mathrm{p} .10$ & 1.2810 \\
\hline
\end{tabular}

Notes:

1. $\quad \mathrm{CL}=$ Constant Load

2. Crack growth rate of $1.0 \mathrm{E}-11$ is used to represent test results where either cracking appeared to cease or the growth rate seemed to arrest.

3. Each of the values in the column "Calculated " $n$ " value" is calculated from Eq. 11.

It can be determined from the $n$ values in the last column of Table 1 that the mean value of $n$, $\mathrm{n}_{\text {MEAN, }}$, is 1.304 and the standard deviation (SD), $\mathrm{n}_{\mathrm{SD}}$, is 0.160 . Based on these mean and standard deviation, a normal distribution for " $n$ " can be constructed. The $n$ values at various percentiles, truncated at $\pm 2(\mathrm{SD})$, are listed in Table 2 .

The base case slip dissolution/film rupture SCC model developed for Alloy 22, represented by Eq. 11, is graphically illustrated in Fig. 5 for $n$ values at 0.984 ( -2 standard deviation), 1.304 (mean), and 1.624 ( +2 standard deviation), along with test data presented in Table 1 and the graphical representation of Eq. 11 for stainless steel (with $n=0.54$ ). Excellent resistance to SCC for Alloy 22 is clearly illustrated in Fig. 5 where even the higher crack growth rates exhibited by 
the top curve of Alloy 22 with $n=0.984$ ( -2 standard deviation) are about 2 orders of magnitude lower than the crack growth rates associated with stainless steel curve.

Table 2. Distribution of the parameter " $n$ "

\begin{tabular}{|c|c|}
\hline n-value & Percentile \\
\hline $0.984(-2 \mathrm{SD})$ & 2.28 \\
\hline 1.041 & 5.00 \\
\hline 1.099 & 10.00 \\
\hline 1.139 & 15.00 \\
\hline $1.144(-1 \mathrm{SD})$ & 15.87 \\
\hline 1.170 & 20.00 \\
\hline 1.221 & 30.00 \\
\hline 1.264 & 40.00 \\
\hline $1.304(\mathrm{Mean})$ & 50.00 \\
\hline 1.345 & 60.00 \\
\hline 1.388 & 70.00 \\
\hline 1.439 & 80.00 \\
\hline $1.464(+1 \mathrm{SD})$ & 84.13 \\
\hline 1.470 & 85.00 \\
\hline 1.509 & 90.00 \\
\hline 1.568 & 95.00 \\
\hline $1.624(+2$ SD) & 97.72 \\
\hline
\end{tabular}

\section{THRESHOLD STRESS INTENSITY FACTOR}

The theory of threshold stress intensity factor assumes that there exists a threshold value of the stress intensity factor $\left(\mathrm{K}_{\mathrm{ISCC}}\right)$ such that any pre-existing crack will not grow or is in an arrest state if the stress intensity factor, $\mathrm{K}_{\mathbf{I}}$, corresponding to the crack size and the applied stress does not exceed $\mathrm{K}_{\mathrm{ISCC}}$. Pre-existing cracks are usually caused by manufacturing processes (especially welding) or crack initiation.

The concept of threshold stress intensity factor $\left(\mathrm{K}_{\mathrm{ISCC}}\right)$ has been commonly used to assess the susceptibility of material to SCC. The description of this concept can be found in Jones and Ricker (1987) and Sprowls (1987). The threshold stress intensity factor (KISCC) is normally determined experimentally. Such experiments, which require very long test time and extremely high accuracy in measurement, are unpractical for Yucca Mountain Project applications. As an alternative approach, a crack blunting criterion is used to define the threshold stress intensity factor. Based on the crack blunting criterion (Andresen and Ford 1985), the crack tip must propagate faster than the dissolution rate on the unstrained crack sides. If this criterion is not fulfilled, the sharp crack will degenerate to a blunt pit. It follows that an SCC crack will not grow if the general corrosion rate at the crack sides exceeds the crack tip growth rate. If $\mathrm{V}_{\mathrm{gc}}$ is the general corrosion (GC) rate, the threshold stress intensity factor $\mathrm{K}_{\mathrm{ISCC}}$ can be calculated from Eq. 12 , or the following equation: 


$$
\mathrm{K}_{\mathrm{ISCC}}=\left(\mathrm{V}_{\mathrm{gc}} / \bar{A}\right)^{1 / \bar{n}}
$$

The general corrosion rate, based on CRWMS M\&O (2000), at the $50^{\text {th }}$ percentile is about 50 $\mathrm{nm} / \mathrm{y}$, the rate at $90^{\text {th }}$ percentile is $100 \mathrm{~nm} / \mathrm{y}$, and the maximun rate measured is $731 \mathrm{~nm} / \mathrm{y}$.

\section{MITIGATION OF WELD RESIDUAL STRESS}

SCC can be reduced to a manageable state if the weld residual stress in the WP can be effectively mitigated. For the final closure welds of the WP, non-thermal mitigation (laser peening or lowplasticity burnishing) can be applied without heating the spent fuel elements within the WP. The laser peening treatment, which will be used for the $25-\mathrm{mm}$ outer lid of the outer barrier, involves use of the laser peening process, where a high powered laser beam introduces shock pulses on the material surface. Laser peening is similar to the traditional shot-peening procedure but is a much-improved technology. For laser peening, the intense stream of tiny metal or ceramic balls used in the traditional shot peening is replaced by high-energy lasers with pulse lengths in the tens of nanoseconds, short enough to generate a rapid yet energetic shock. This process can produce a uniform layer of highly shocked and compressed material that is extremely resistant to cracks and corrosion. According to measured data reported in Hornbach (1999), laser peening is capable of producing a compressive surface layer of about 60 mils $(1.5 \mathrm{~mm})$ with compressive stress in the range of 20 to $60 \mathrm{ksi}$ for a one inch thick Alloy 22 plate. The depth of stress reduction may be increased by repeated application of laser peening (Hornbach 1999).

To demonstrate the effect of laser peening on the stress intensity factor, the weld induced residual stress in the 25-mm outer lid of the CRM-21 PWR WP design was reduced from tensile stress to $40 \mathrm{ksi}$ compression stress for a depth of 0.06 in at the outside surface (see Fig. 6). The residual stress then varies linearly from 0.06 in. to 0.12 in. From this point on, the stress remains undisturbed. The stress intensity factor was calculated for the reduced stress profile and compared to the stress intensity factor previously calculated for the original stress profile as shown in Fig. 7.

\section{CONCLUSIONS}

This paper deals with the description of the process-level model (see Fig. 2) developed for the performance assessment of the Alloy 22 waste package outer barrier subjected to stress corrosion cracking due to weld induced stress in the final closure welds. A threshold stress is determined for the purpose of dealing with crack initiation based on available test data. The slip dissolution/film rupture model relates crack initiation and the subsequent advance to the metal oxidation that occurs when the protective film at the crack tip is ruptured. The slip dissolution/ film rupture model can be applied to assess the failure (or the lack of it) of the waste package due to the SCC crack propagation for given manufacturing cracks and/or cracks initiated by the combined effects of stress and environment. The threshold stress intensity factor (SIF) is based on the theory that there exists a threshold value $\left(\mathrm{K}_{\mathrm{ISCC}}\right)$ for the stress intensity factor such that there is no growth of a pre-existing crack or flaw having a stress intensity factor less than the threshold value. The threshold SIF provides a criterion for determining if an SCC crack will reach an arrest state or enter a propagation phase. SCC can be reduced to a manageable state if the weld residual stress in the WP can be effectively mitigated. For the final closure welds of the WP, non-thermal mitigation (laser peening or low-plasticity burnishing) can be applied without 
heating the spent fuel elements within the WP. Laser peening has been demonstrated to be an effective stress mitigation technique.

\section{REFERENCES}

Andresen, P.L.; Emigh, P.W.; Young, L.M.; and Gordon, G.M. 2003. "Stress Corrosion Cracking Growth Rate Behavior of Alloy 22 (UNS N06022) in Concentrated Groudwater." Corrosion 2003. The annual conference and corrosion show sponsored by NACE International. Paper No. 03683.

Andresen, P.L. and Ford, F.P. 1985. "Modeling and Life Prediction of Stress Corrosion Cracking in Sensitized Steel in High Temperature Water." Predictive Capabilities in Environmentally Assisted Cracking. American Society of Mechanical Engineers (ASME) Publication PVP-Vol 99. 17-38.

Andresen, P.L. and Ford, F.L. 1988. "Life Prediction by Mechanistic Modeling and System Monitoring of Environmental Cracking of Iron and Nickel Alloys in Aqueous Systems." Materials Science and Engineering, A103, 167-184.

ASM International. 1987. Corrosion. Volume 13 of Metals Handbook. 9th Edition.

ASME (American Society of Mechanical Engineers) 1969. Criteria of the ASME Boiler and Pressure Vessel Code for Design by Analysis in Section III and VIII, Division 2. The American Society of Mechanical Engineers. 1969, Library of Congress Catalog Card Number 56-3934.

BSC (Bechtel SAIC Company) 2001. Environment on the Surfaces of the Drip Shield and Waste Package Outer Barrier. ANL-EBS-MD-000001 REV 00 ICN 02. Bechtel SAIC Company, Las Vegas, Nevada.

BSC (Bechtel SAIC Company) 2003. Analysis of Mechanisms for Early Waste Package/Drip Shield Failure. CAL-EBS-MD-000030 REV 00. Bechtel SAIC Company, Las Vegas, Nevada.

CRWMS M\&O 1996. Waste Package Closure Weld Development Report. BBA000000-017172500-00006 REV 00. Civilian Radioactive Waste Management System (CRWMS) Management and Operation Contractor (M\&O), Las Vegas, Nevada.

CRWMS M\&O 2000. General Corrosion and Localized Corrosion of Waste Package Outer Barrier. ANL-EBS-MD-000003 REV 00. Civilian Radioactive Waste Management System (CRWMS) Management and Operation Contractor (M\&O), Las Vegas, Nevada.

DOE (U.S. Department of Energy) 2001. Yucca Mountain Science and Engineering Report. DOE/RW-0539. Washington, D.C.: U.S. Department of Energy, Office of Civilian Radioactive Waste Management. May 2001.

Ford, F.P. and Andresen, P.L. 1988. "Development and Use of a Predictive Model of Crack Propagation in 304/316L, A533B/A508 and Inconel 600/182 Alloys in $288^{\circ} \mathrm{C}$ Water." Environmental Degradation of Materials in Nuclear Power Systems-Water Reactors, 
[Proceedings of the Third International Symposium, Traverse City, Michigan, August 30September 3, 1987]. Theus, G.J. and Weeks, J.R., eds. Pages 798 - 800.

Hornbach, D.J. 1999. X-Ray Diffraction and Ring-Core Determination of the Residual Stress Distributions in One(1) Alloy C22 Welded Plate and One (1) Alloy C22 Test Bar. 1034-8520. Lambda Research, Cincinnati, Ohio.

Jones, R.H. and Ricker, R.E. 1987. "Stress-Corrosion Cracking." Metals Handbook Ninth Edition. Volume 13. Corrosion . 145-163.

Sprowls, D.O. 1987. "Evaluation of Stress-Corrosion Cracking." Metals Handbook Ninth Edition. Volume 13. Corrosion. 245-282.

Young, L.M; Catlin, G.M.; Andresen, P.L.; and Gordon, G.M. 2003. "Constant Load SCC Initiation Response of Alloy 22 (UNS N06022), Titanium Grade 7 and Stainless Steels at $105^{\circ} \mathrm{C}$." Corrosion 2003. The annual conference and corrosion show sponsored by NACE International. Paper No. 03685.

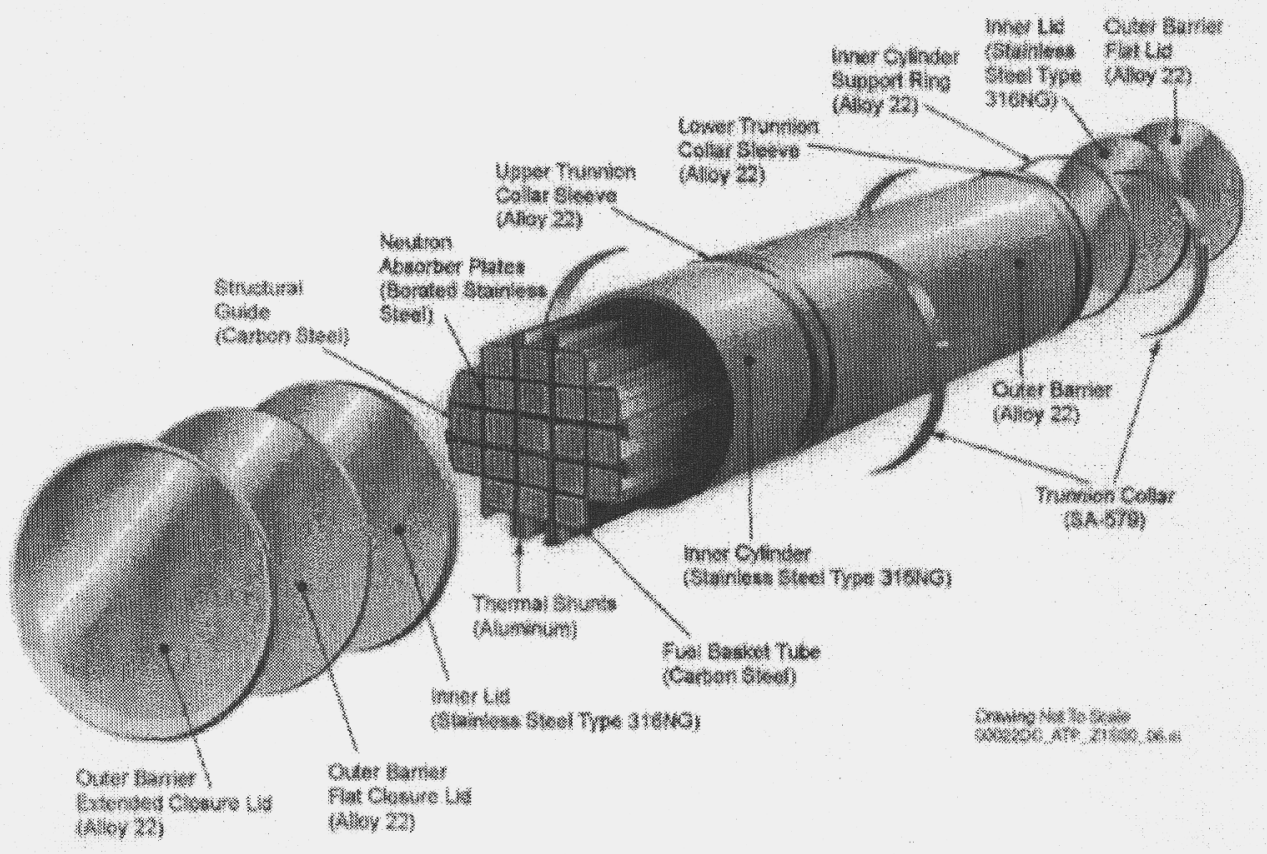

Fig. 1. Typical Waste Package Used for Yucca Mountain Repository. 


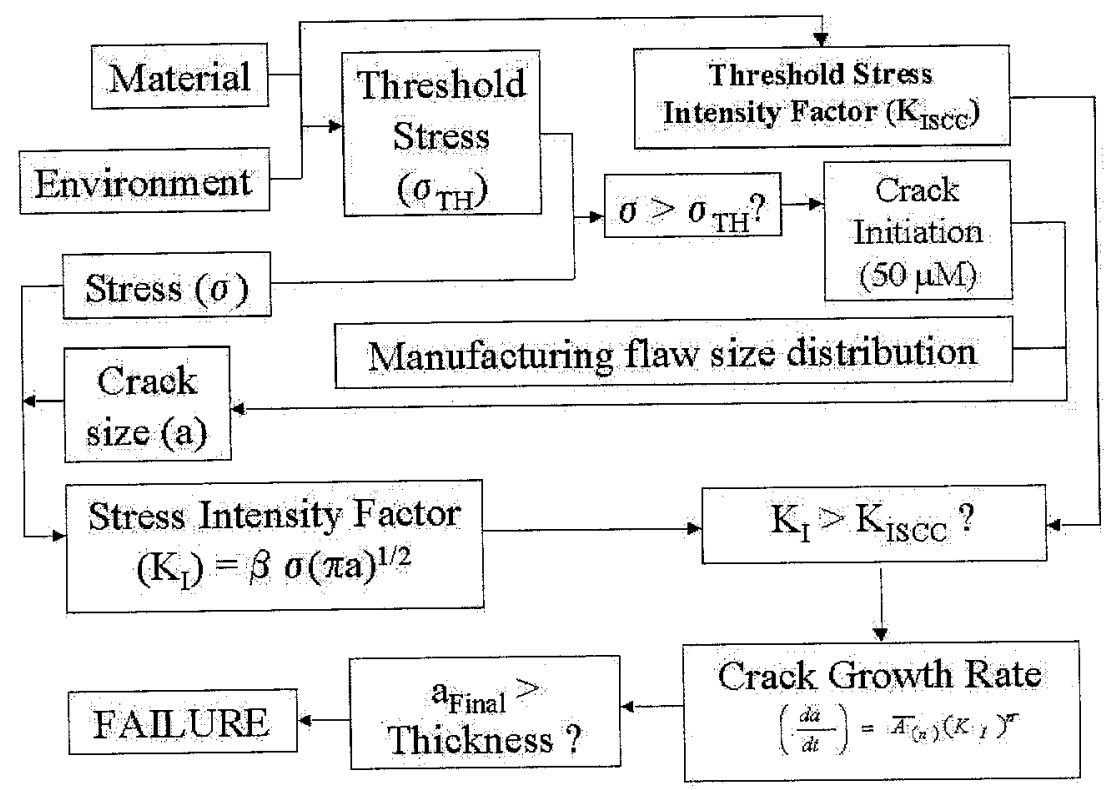

Fig. 2. Flow Diagram for Treatment of Stress Corrosion Cracking.

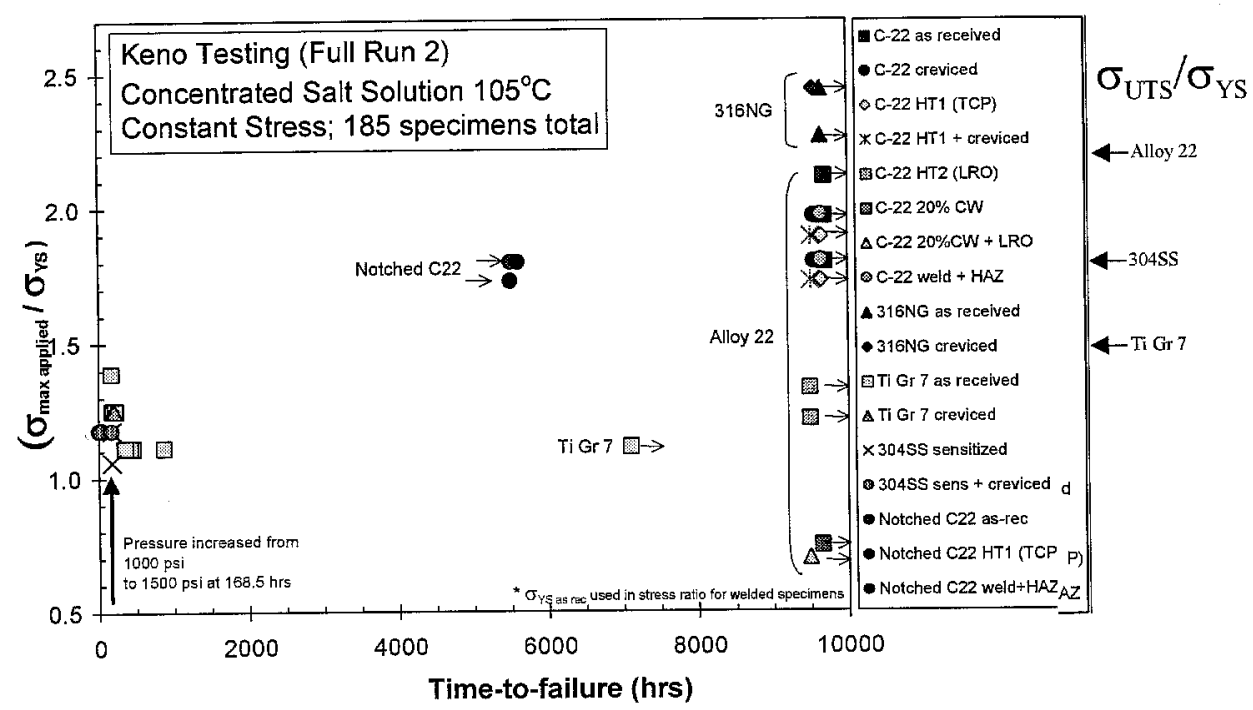

Fig. 3. Failure Stress vs. Time-to-Failure Plot for Crack Initiation Tests. 


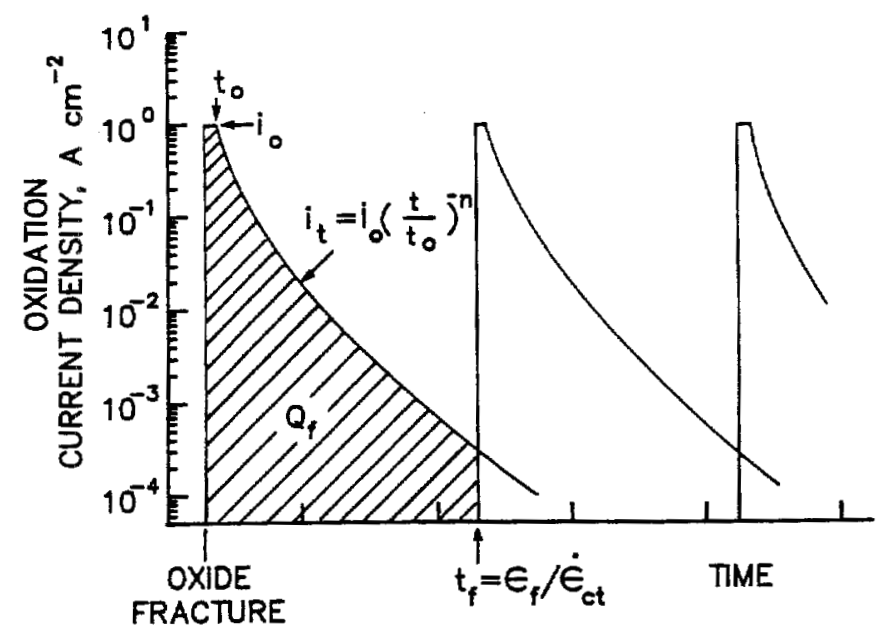

$V=\frac{d a}{d t} ; V_{o v}=\frac{M}{Z s F} \cdot \frac{Q_{i}}{t_{f}}$

FOR HIGH $\dot{\epsilon}_{\mathrm{ct}}$ AND/OR LONG to:

$\begin{aligned} & \bar{V}_{a v}=\frac{M}{Z S F} \cdot i_{0} \\ & \text { FOR LOW } \dot{\epsilon}_{c t} \text { AND/OR SHORT } t_{0}: \\ & \bar{V}_{o v}=\frac{M}{Z 5 F} \frac{i_{0} t_{0}^{n}}{(1-n) \epsilon_{f}^{n}} \dot{\epsilon}_{c t}^{n} \\ &=f(n) \dot{\epsilon}_{c t}^{n}\end{aligned}$

Figure 4. Oxidation Current Density Vs. Time Following Repeated Oxide Ruptures.

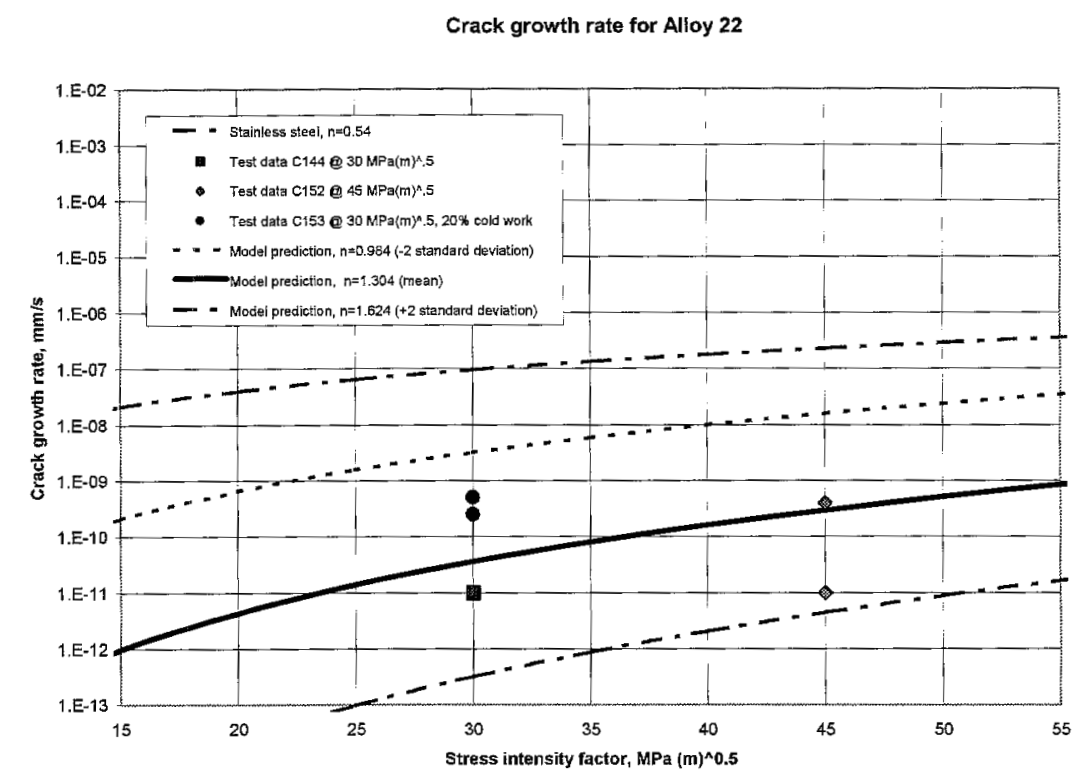

Figure 5. Crack growth rate vs. stress intensity factor for Alloy 22 based on the SDFR model. 
(a)

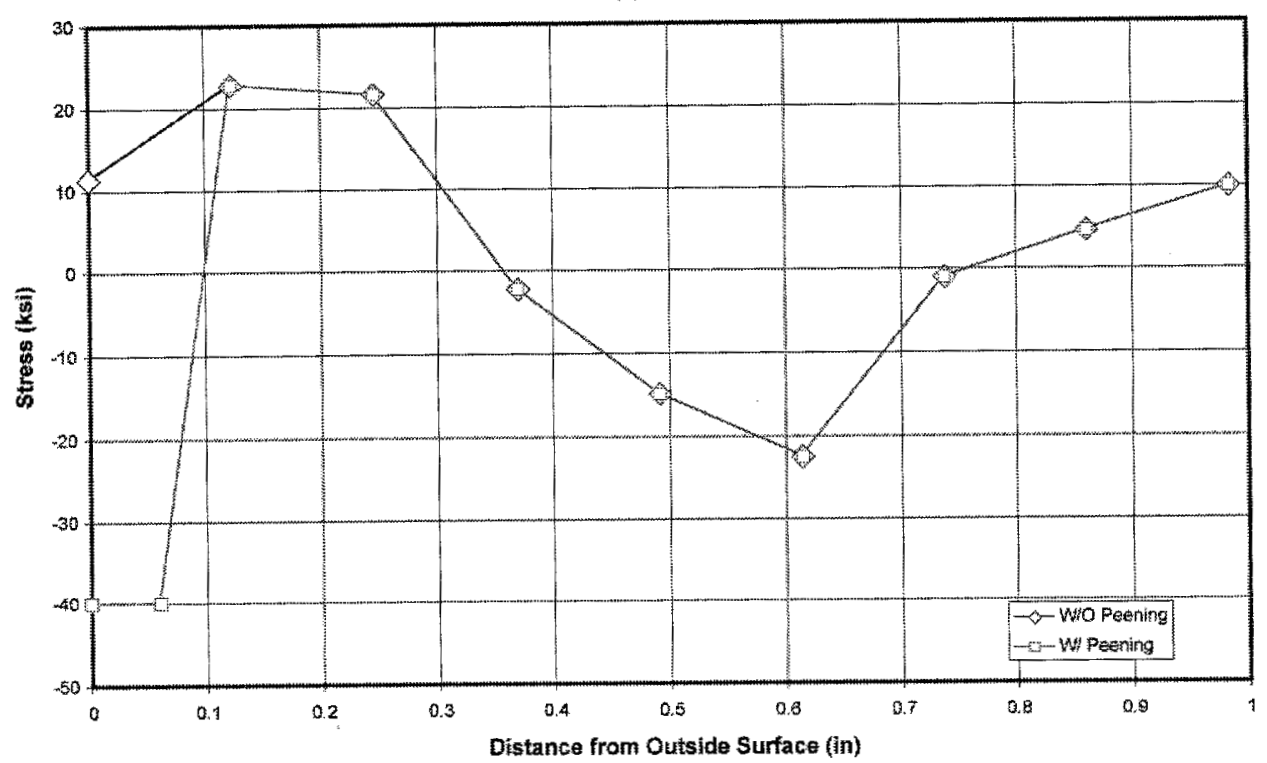

(b)

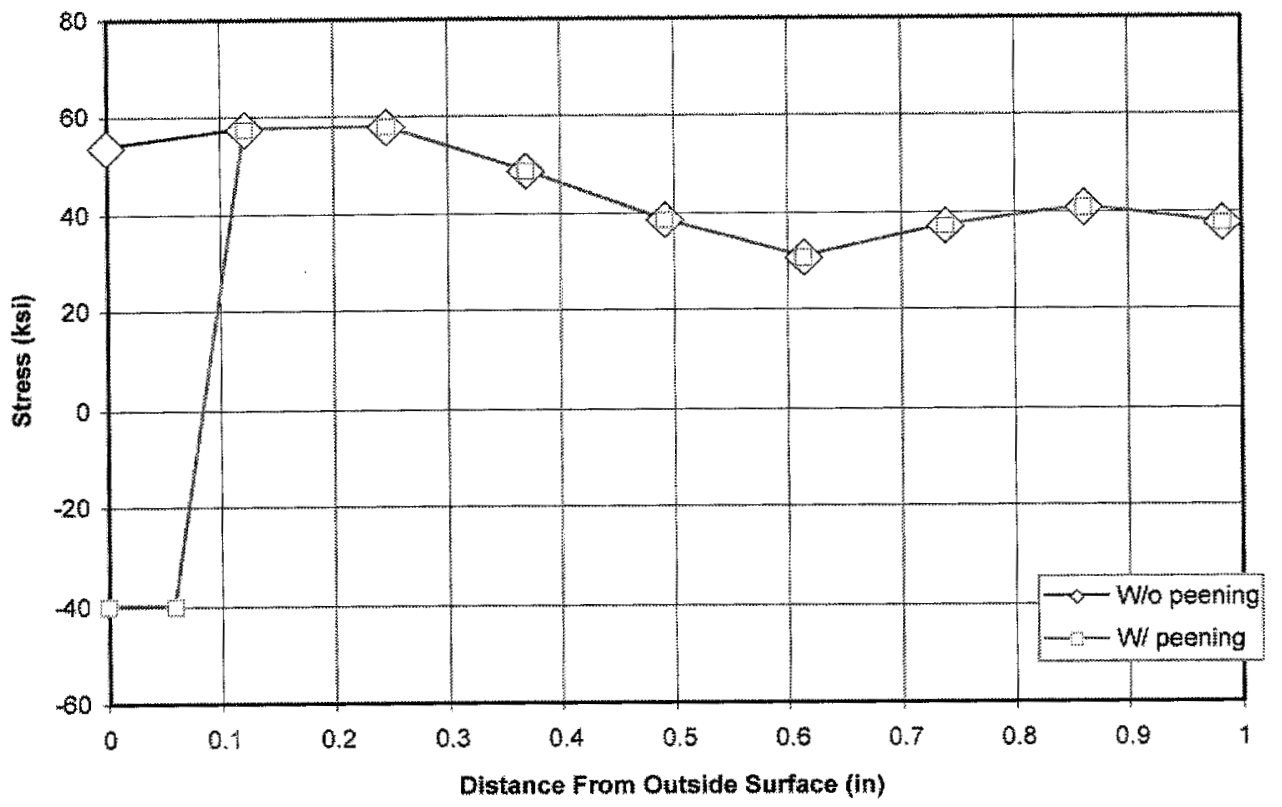

NOTE: (a) Radial Stress, Sx

(b) Hoop Stress, Sz

Figure 6. Stress in Outer Lid with and without Laser Peening. 
(a)

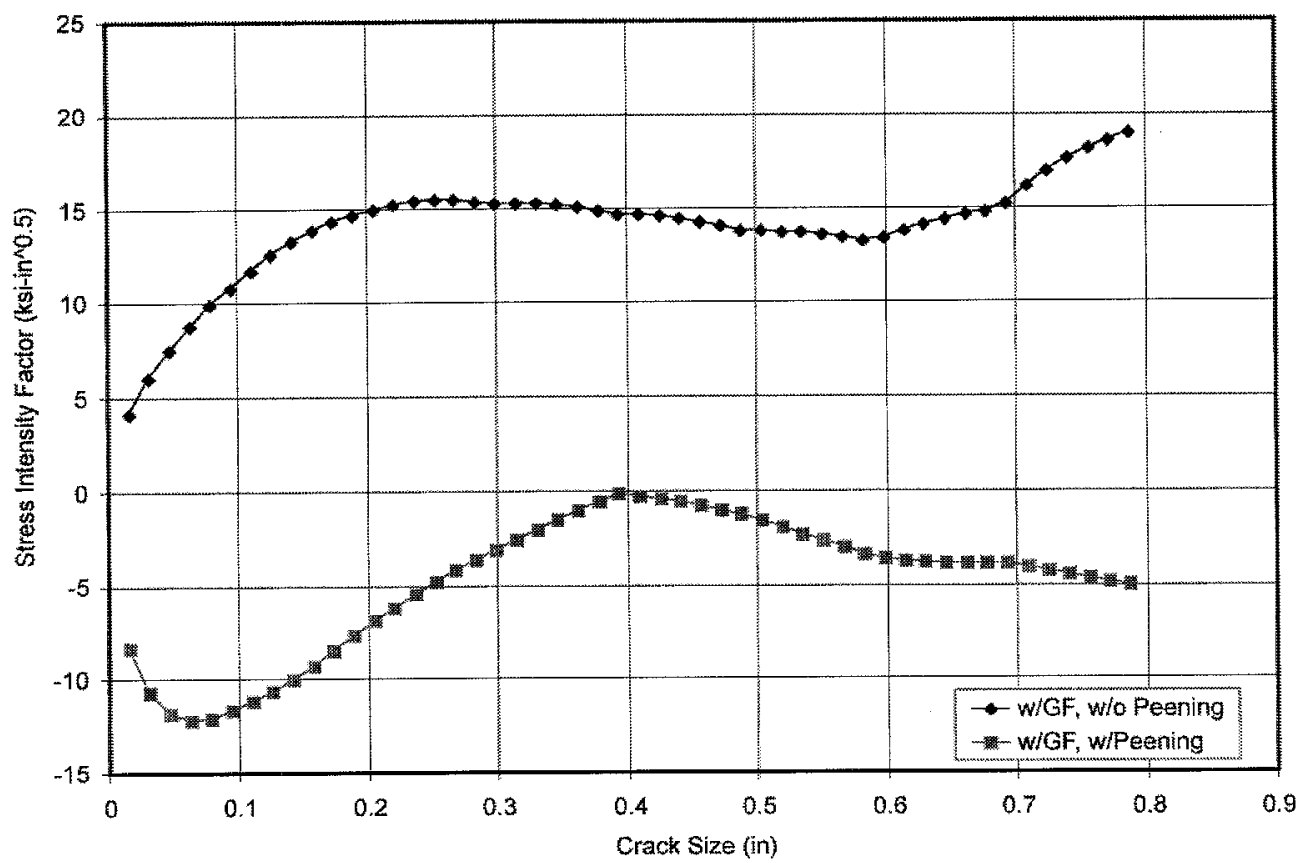

(b)

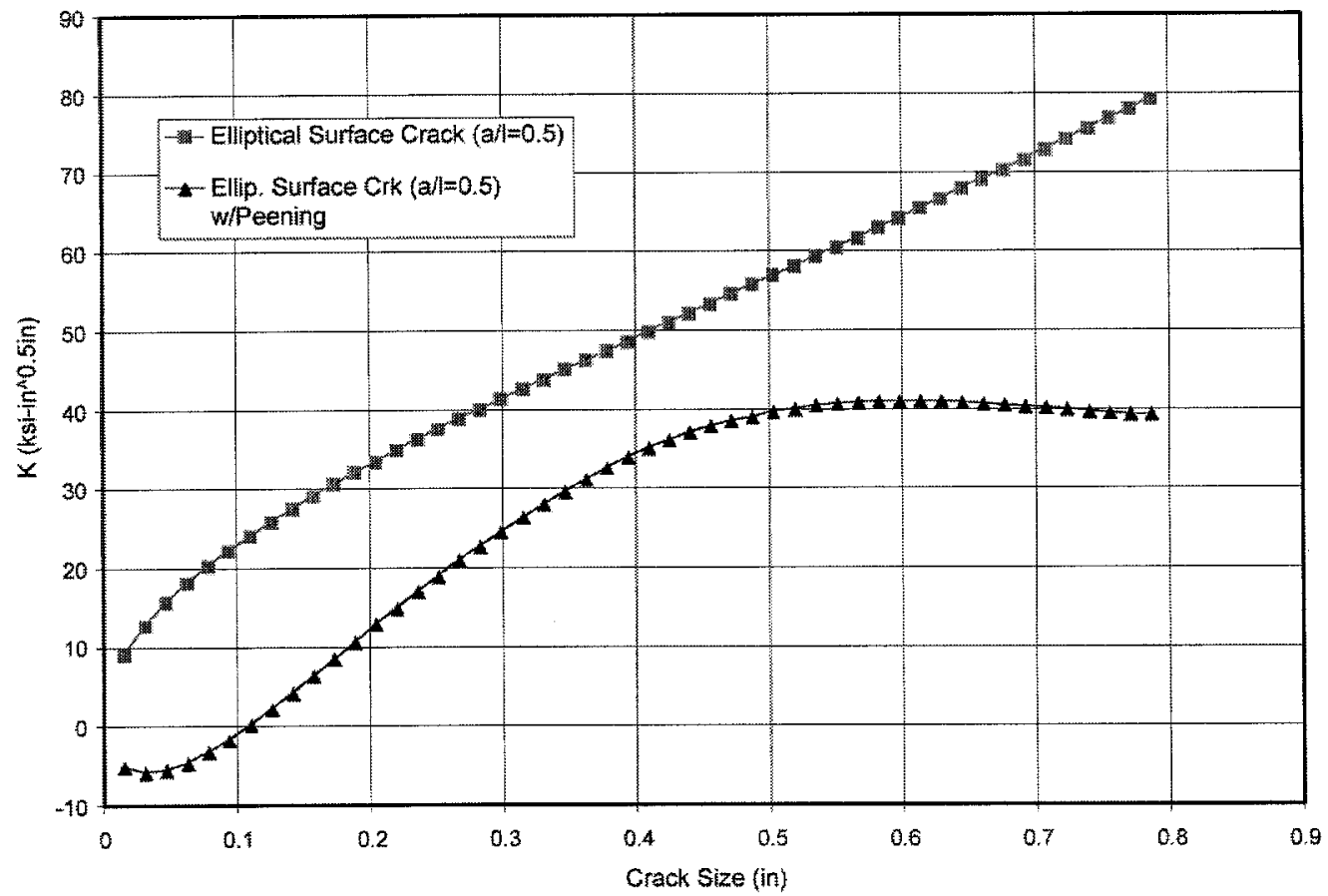

NOTE: (a) Stress Intensity Factor Plots due to Radial Stress

(b) Stress Intensity Factor Plots due to Hoop Stress

Fig. 7. Stress Intensity Factors with and without Laser Peening. 